\title{
Gênero, território e decolonialidade: experiências e perspectivas no Brasil
}

\author{
Gender, territory and decoloniality: experiences and perspectives from Brazil
}

\author{
Natália Tavares de Azevedo ${ }^{1}$ \\ Katya Regina Isaguirre-Torres ${ }^{2}$ \\ Carolina dos Anjos de Borba ${ }^{3}$
}

\section{Introdução}

Nas últimas décadas, no Brasil e em toda a América Latina, tem se observado uma intensificação de conflitos territoriais e socioambientais envolvendo comunidades tradicionais, camponeses, povos originários e outros grupos que têm em sua territorialidade condição fundamental para reprodução da vida. Tal intensificação decorre dos modelos hegemônicos de "desenvolvimento" que têm sido historicamente impostos à América Latina, expressão da colonialidade do poder constitutiva do sistema-mundo moderno/colonial/capitalista/patriarcal (GROSFOGUEL, 2008), baseado na classificação social, hierarquização e subalternização racial, de gênero e de classe (QUIJANO, 2005).

Em sua face atual, este sistema-mundo e sua matriz global de poder, com sua divisão internacional do trabalho, põe em marcha práticas neoextrativistas em todo o continente latinoamericano. Nesse "modelo de desenvolvimento" são impulsionados empreendimentos ligados à produção de commodities da mineração e do agronegócio, além de obras de infraestrutura viária e energética de suporte à essas atividades (MACHADO ARÁOZ, 2011; MANRIQUE, 2015; MERCHAND ROJAS, 2016).

Em tal processo expansivo, diversas comunidades - até então situadas à margem dos processos dominantes de acumulação de capital - se vêm despojadas de seus territórios, com seus

\footnotetext{
${ }^{1}$ Doutora em Meio Ambiente e Desenvolvimento. Bolsista do Programa Nacional de Pós-doutorado (PNPD/CAPES) junto ao Programa de Pós-graduação em Desenvolvimento Territorial Sustentável - PPGDTS/UFPR. Professora colaboradora do Programa de Pós-graduação em Meio Ambiente e Desenvolvimento - PPGMADE/UFPR. E-mail: natytav@yahoo.com.br

${ }^{2}$ Doutora em Meio Ambiente e Desenvolvimento, professora adjunta do departamento de Direito Público da Faculdade de Direito da Universidade Federal do Paraná. E-mail: kisaguirre@gmail.com

${ }^{3}$ Doutora em Desenvolvimento Rural. Professora adjunta na Universidade Federal do Paraná, no Setor de Educação e nas Pós-Graduações em Educação/UFPR, Meio Ambiente e Desenvolvimento/UFPR; Ciências Sociais/UNI-CV. E-mail: carolzinhadosanjos@gmail.com
} 
bens comuns privatizados. Trata-se de processos identificados por Harvey (2014) como de acumulação por espoliação, nos quais os bens comuns como a terra, a água e o ar são convertidos em mercadorias e submetidos à apropriação privada. Longe ser um fenômeno exclusivo dos momentos iniciais do capitalismo - como acumulação primitiva - são identificados até hoje na geografia histórica do capitalismo, mecanismos centrais de resposta do capital diante de uma crise estrutural (MÉSZÁROS, 2009).

O que se observa é a imposição desigual dos custos do processo de acumulação de capital e crescimento econômico. Além de comunidades expulsas de seus territórios, as chamadas "externalidades" - poluição, contaminação -, produtos invendáveis da atividade capitalista, são também desigualmente alocados no espaço - as plantas industriais poluidoras e degradadoras e os riscos ambientais são, em geral, situados nas proximidades de áreas "periféricas" nas quais, por conta da dinâmica do mercado de terras, vivem as populações socialmente vulnerabilizadas (ACSELRAD, 2013), configurando situações de desigualdade e injustiça ambiental nas chamadas zonas de sacrifício. Essas populações são, de forma recorrente, aquelas racializadas no moderno sistemamundo - negros, indígenas, comunidades tradicionais - configurando situações de racismo ambiental (PACHECO; FAUSTINO, 2013).

É importante salientar, contudo, que essa ofensiva espoliadora do capital em sua fase atual não ocorre sem resistências. Tem-se observado distintas formas de lutas e r-existência desses grupos sociais, que, muito além de meramente reativos, anunciam e demandam novas formas de vida, na qual a busca por autonomia, emancipação e reconhecimento de sua diversidade histórica, cultural e social ganham relevo. Aqui as categorias colonialidade e decolonialidade ganham mais destaque. A leitura dos processos a partir dessa chave interpretativa nos leva a destacar a pluralidade e a diversidade de formas de ser, de viver e de conhecer que buscam garantir a possiblidade de outros mundos possíveis. Sem negar o papel fundamental que a economia tem na constituição do sistemamundo moderno colonial capitalista, a perspectiva da des/colonialidade constituída desde o pensamento latino-americano busca apontar para as dimensões culturais, epistemológicas e étnicas que são constitutivas desse mesmo sistema-mundo.

Assim, pode-se argumentar, com Porto-Gonçalves e Quental (2012), que embora a perspectiva teórica da acumulação por espoliação como forma de caracterizar o Novo Imperialismo no atual estágio do sistema-mundo capitalista seja imprescindível, ela é insuficiente se ignorar a colonialidade que atravessa o sistema-mundo desde seus primórdios até hoje. A classificação social pautada na racialização - e no gênero - foi e é constitutiva desse moderno sistema-mundo capitalista, operando 
de forma simultânea com a subordinação do trabalho ao capital, tendo a América Latina um papel central em sua constituição ${ }^{4}$.

O pensamento de Aníbal Quijano sobre a colonialidade do poder estabeleceu as bases para um conjunto de produções que passaram a destacar as relações estruturais entre as diversas “modalidades moderno/coloniais de classificação social ('raça', 'gênero', classe) e as dinâmicas de dominação e exploração, tanto material quanto subjetiva, em que se tornaram tais modalidades" (BORSANI; QUINTERO, 2014).

Como aponta Mignolo (2014), modernidade/colonialidade e descolonialidade são três palavras distintas, mas que expressam um só conceito verdadeiro. Trata-se de uma tríade que nomeia um conjunto complexo de relações de poder. Colonialidade é equivalente a matriz ou padrão colonial de poder, um complexo de relações que se esconde detrás da retórica da modernidade (o relato da salvação, progresso e felicidade) que justifica a violência (MIGNOLO, 2014). E a decolonialidade é a resposta necessária tanto às falácias e ficções das promessas de progresso e desenvolvimento que implica tanto a modernidade quanto a violência da colonialidade.

Como aponta Quijano (2015), a descolonialidade do poder é o ponto de partida, contra todas as formas de dominação e exploração, tendo como eixo de orientação as práticas sociais da autoprodução e reprodução democráticas da existência social. Trata-se de um posicionamento epistêmico-político em que a modernidade eurocentrada e sua pretensa universalidade é colocada em questão, e a partir da qual as resistências apontam para o pluriverso, onde coexistam diversos mundos sócio-naturais (ESCOBAR, 2012).

Nesse caminho, destaca-se o papel que as mulheres têm tido nessas lutas, com forte presença nos movimentos e organizações sociais que denunciam a violação de seus direitos - entre indígenas, camponeses, quilombolas, pescadoras, mulheres negras e trabalhadoras urbanas - e os diversificados sujeitos sociais que têm ganhado visibilidade na luta por território. Esse destaque revela não a expressão de um essencialismo, das mulheres como reflexo passivo da terra, mas sobretudo da terra lhes servindo ativamente em sua representação de liberdade e emancipação (BELAUSTEGUIGOITIA RIUS, 2011; SEGATO, 2012).

Neste volume, foram selecionados 10 artigos que versam sobre distintas temáticas que orbitam em torno das questões de gênero, território, raça, etnia, campesinato, movimentos sociais, resistência e colonialidade, provocados pela chamada a este dossiê. Ainda que nem todos assumam diretamente

\footnotetext{
${ }^{4}$ Para uma melhor compreensão da constituição do grupo modernidade/colonialidade e do giro decolonial latinoamericano, ver América Latina e o giro decolonial de Luciana Balestrin (2013).
} 
a perspectiva da modernidade/colonialidade, convergem na crítica às novas e velhas formas de colonialidade desenhadas desde o "Ocidente Imperial” (BORSANI, QUINTERO, 2014). Neste texto introdutório, condensamos algumas lições trazidas pelos artigos selecionados, tematizados em três seções: Regimes agrários e agroalimentares e formas de resistência no campo: a agroecologia e o patrimônio agroalimentar; Mulheres dos campos e das águas, empoderamento e território; e População negra e quilombola e o lugar da educação.

\section{Regimes agrários e agroalimentares e formas de resistência no campo: a agroecologia e o patrimônio agroalimentar}

Um elemento central da expressão do neoextravismo e da forma de inserção do Brasil no sistema mundo moderno/colonial/capitalista se dá pela centralidade da economia do agronegócio no país. Como apontado no artigo apresentado por Silva e Archanjo (2019), "Despindo preconceitos: (re)conhecendo os movimentos sociais no Brasil através de suas lutas pela reforma agrária", o agronegócio brasileiro integra uma cadeia que tem se constituído por meio de impérios alimentares (PLOEG, 2008), atrelados à uma agricultura industrializada que fundamenta uma alimentação padronizada.

$\mathrm{O}$ atual sistema agroalimentar, denominado regime agroalimentar corporativo por McMichael (2016) tem como característica, segundo o autor, o estabelecimento da hegemonia corporativa sustentada por finanças internacionais e regras multilaterais, situando os mercados acima do Estado, que se tornam servidores dos mercados, por meio de governança financeira internacional do Banco Mundial/Fundo Monetário Internacional (FMI) e da Organização Mundial do Comércio (OMC). Tal configuração resulta em um regime alimentar privado, constituído por corporações transnacionais institucionalizado no livre-comércio e visionado em um mercado de "segurança alimentar".

Segundo Ploeg (2008):

A atual crise agrária emerge a partir da interação entre (1) a parcial, ainda que progressiva, industrialização da agricultura, (2) a introdução do mercado global como princípio ordenador da produção e comercialização agrícola e (3) a reestruturação da indústria de processamento, de grandes empresas de comercialização e de cadeias de supermercados em impérios alimentares que exercem um poder monopólico crescente sobre as relações que encadeiam a produção, o processamento, a distribuição e o consumo de alimentos. A fusão desses três processos, criando um novo e global regime alimentar, está afetando profundamente a natureza da produção agrícola, os ecossistemas nos quais a agricultura está enraizada, a qualidade do alimento e as suas formas de distribuição. 
No Brasil, esse regime está enraizado, expresso pela economia do agronegócio focado nas commodities, como a soja, para exportação e por um modelo agrícola que, desde a modernização conservadora (DELGADO, 2012), tem se fundamentado no pacote de insumos que industrializa a agricultura a partir de uma pretensa lógica científica - sementes, agrotóxicos, fertilizantes. Esse modelo de "desenvolvimento" no campo tem gerado intensos impactos ambientais e inúmeros conflitos, inclusive violentos. Concentração fundiária, degradação da biodiversidade e destruição da sociodiversidade, envenenamento e violência contra comunidades que lutam pela terra são consequências desse regime agroalimentar corporativo (CARNEIRO et al., 2015).

Nesse contexto, a luta pela terra por parte dos movimentos sociais que têm como foco a reforma agrária, como apontado por Silva e Archanjo (2019), se constitui como um elemento de resistência a esse regime alimentar corporativo, indo além da questão fundiária. É também uma luta por soberania alimentar, de direito de acesso dos povos a alimentos saudáveis (livre de agrotóxicos) e culturalmente adequados, acessíveis, produzidos de forma sustentável e ecológica, bem como pelo direito de decidir seu próprio sistema alimentar e produtivo.

Como colocam Rodrigues et al. (2019), no artigo “Campesinato e sementes crioulas: indícios de decolonialidade" apresentado neste dossiê, a Agroecologia emerge também como possível resposta decolonial ao regime alimentar corporativo e a economia do agronegócio. Não se trata apenas de outra prática produtiva mercantil mais adequada ao meio ambiente, mas uma que busca se fundamentar em outras perspectivas epistemológicas, contra o desperdício da experiência, nos termos de Boaventura de Sousa Santos (2007). O agronegócio, sustentado por uma ciência comprometida com interesses econômicos hegemônicos, contribui para o silenciamento e a morte de saberes outros, que coevoluíram na relação dos camponeses com a natureza. Os autores dão destaque à dimensão epistemológica das práticas agroecológicas e seu manejo das sementes crioulas contra o epistemicídio, pela valorização das práticas e saberes dos camponeses, agricultores familiares e comunidades tradicionais.

No texto de Balestrin (2019), "Algumas reflexões acerca das jovens camponesas, agroecologia e decolonialidade” que compõe esta coletânea, aborda-se as questões de gênero que envolvem as famílias de agricultores familiares, nas quais ainda prevalece um modelo patriarcal que leva, inclusive, ao êxodo das mulheres do campo. Além de alijadas dos processos de decisão da unidade familiar, muitas vezes as mulheres são também excluídas da sucessão da terra, em favor de seu papel restrito ao de mães e esposas. Segundo a autora, recorrendo a Siliprandi (2015), a 
agroecologia valoriza as práticas tradicionalmente desenvolvidas pelas mulheres, como hortas, pomares, criação de pequenos animais, propiciando seu envolvimento no processo produtivo. Nesse sentido, a agroecologia contribui para desestabilizar esses papéis atribuídos às mulheres pela lógica patriarcal no campo, ao reconhecer as atividades produtivas da mulheres como geradoras de trabalho e valor, e não mera “ajuda".

Ainda sob a perspectiva da alimentação e sua relação com as mulheres, Silva e Gabriel (2019), em seu texto "O impacto da colonização europeia na alimentação e o papel da mulher indígena na conservação do patrimônio alimentar", nos apresentam reflexões sobre as alterações no modelo alimentar entre os M'bya Guarani como resultado dos processos de colonização - e da colonialidade - estabelecida a partir de perspectivas eurocentradas. Um aspecto central para compreensão dos impactos desses processos no patrimônio alimentar dos Guarani é a questão dos direitos territoriais. As autoras indicam que a falta de acesso ao território leva a desestruturação da cultura alimentar M’bya, uma vez que inviabiliza a cultura dos seus principais alimentos - como a mandioca - e a prática da caça e pesca. Esses alimentos tradicionais dos guaranis são substituídos por aqueles distribuídos por medidas socioassistenciais - as cestas básicas - que trazem macarrão, biscoitos, sal e açúcar para a pauta alimentar dos indígenas, incluindo-se aí a alimentação das crianças no âmbito escolar. Porém, os guaranis também expressam suas ações de resistência, mais uma vez com protagonismo feminino, buscando manter seus hábitos tradicionais aprendidos com as suas mais velhas. As autoras apontam, assim, para uma crítica ao modelo de desenvolvimento que, focado apenas no crescimento econômico, exclui e subalterniza os povos originários, como os M'bya, indicando a necessidade de outros paradigmas, mais abrangentes da diversidade das formas de viver.

Ainda na perspectiva da construção de alternativas, Santos e Liboni (2019), no texto "Biocomércio em comunidades tradicionais: uma revisão sistemática”, apontam para valorização dos produtos da biodiversidade brasileira com o desenvolvimento do biocomércio, a partir do princípio da autonomia de povos e comunidades tradicionais. Como apontamentos, verificam várias mudanças sociais nas comunidades ocasionadas pelo aumento da renda, apontando que, apesar de melhorar a condição de vida das famílias, as parcerias continuam suplementares na geração de renda e não centrais. Como consequência, há dependência de agentes econômicos externos e sensibilidade a sazonalidade do mercado. Segundo os autores, na prática, as comunidades perdem valores tradicionais, sofrem diferenciação social, desigualdade econômica e mudança dos hábitos alimentares dos grupos envolvidos. O impacto ambiental decorrente de acordos entre grupos locais e empresas ocorre de forma direta, pelo aumento na extração do recurso explorado para comercialização ou 
indireta, pela inserção de novas tecnologias e exploração dos demais recursos. Por isso, é necessário o desenvolvimento de práticas de biocomércio que apontem caminhos alternativos e não levem à dependência das comunidades envolvidas.

\section{Mulheres dos campos e das águas, empoderamento e território}

Retomando um aspecto central do dossiê, tem-se observado cada vez mais o protagonismo das mulheres na luta pelo território. Tais processos estão entrelaçados a renovadas formas de empoderamento das mulheres em suas localidades, territórios e organizações, rompendo com os papéis de gênero estabelecidos pelo patriarcado.

Há abundante literatura produzida tanto nos circuitos acadêmicos tradicionais, quanto nos polos de produção ligados aos movimentos sociais e a sociedade civil, que abordam essa relação entre a luta pelos territórios e o empoderamento feminino, particularmente na América Latina. Como colocam Rius Belausteguigoitia et al. (2011), as mulheres camponesas e indígenas, por seu vínculo com a terra e seu sentimento de pertencimento ao lugar de origem, se destacam muitas vezes como protagonistas nestas lutas, o que contribui para seu empoderamento no interior de seus movimentos, organizações e comunidades.

Ainda destaca Rius Belausteguigoitia (2011), que em seu processo de liderança, as mulheres se vinculam a duas lutas: a que se refere ao direito à terra e seus recursos e, o mais importante por sua novidade, a que destaca seus direitos em equidade com os homens dentro e fora da comunidade. No marco do pensamento decolonial latino-americano, destacam-se as lutas de mulheres indígenas não apenas em defesa de seus territórios, mas também como pensadoras e analistas desses processos.

Nessa perspectiva ganham relevo autoras/ativistas do feminismo comunitário como Lorena Cabnal (Guatemala) e Julieta Paredes (Bolívia), em que noções como corpo-terra e corpo-território se projetam. Segundo Cruz Hernández (2016), as feministas comunitárias - em que pesem diferenças e pluralidades - abordam o termo corpo-terra para se aprofundar nos danos que foram causados aos territórios desde a invasão colonial que passou da expropriação de suas terras, territórios, recursos e conhecimentos, utilizando como veículo os corpos das mulheres. Porém, igualmente apontam que seria essencialista pensar que a violência e subordinação exercidas sobre as mulheres indígenas só vêm de fora. Segundo Cruz Hernández, recorrendo à Cabnal (2010) e Paredes (2011), elas também são geradas dentro de suas comunidades e não se deram apenas com o fato colonial, mas havia um patriarcado desde antes da colônia. Concluem que para entender a defesa dos territórios das mulheres, 
deve-se compreender o processo histórico do patriarcado. No conceito corpo-terra está subjacente uma demanda política que emana de uma reflexão coletiva das mulheres indígenas para mostrar sua visão na defesa de seus territórios.

É nessa chave interpretativa que trazemos as contribuições desse dossiê. No artigo “Empoderamento de mulheres no sindicalismo de trabalhadores e trabalhadoras rurais de Marabá (PA)”, Reis e Guerra (2019) analisam as transformações da inserção das mulheres no sindicato em Marabá. Abordando questões também apontadas por Balestrin (2019), Reis e Guerra (2019) refletem sobre os papéis de gênero no âmbito das relações no campo, nas propriedades e assentamentos rurais. Embora as mulheres participem ativamente das atividades produtivas, seus papéis são muitas vezes identificados como o de mães e esposas, e sua contribuição nos processos de tomada de decisão minimizados, mesmo no âmbito privado da vida familiar. Já em sua participação nos espaços públicos, veem-se muitas vezes bloqueadas e, como apontam os autores com base em Paulilo (2009), a repressão sexual e a exposição ao ridículo são instrumentos eficazes de controle dos homens em relação às mulheres.

Porém, as mulheres têm sistematicamente buscado romper esses papéis cristalizados, buscando ativamente seu empoderamento no âmbito de suas organizações e comunidades, ocupando cargos de direção e, juntamente com entidades de apoio, promovendo atividades e formações para construir novas relações. Participação na esfera pública e mudança nas relações domésticas são diretamente correlacionados. Um elemento fortemente destacado é o relacionado à violência doméstica. Segundo os autores, esses aspectos mostram o caráter processual do empoderamento, processo complexo e marcado por contradições, avanços e recuos.

Mafra (2019) e Yamaoka et al. (2019) nos trazem duas experiências em que as mulheres assumiram o protagonismo na luta pelo território de comunidades pesqueiras. Yamaoka et al. (2019), em seu artigo "A comunidade caiçara da Enseada da Baleia e a sua luta pelo território - Cananéia (SP)", versam sobre o processo de luta da comunidade da Enseada da Baleia, na Ilha do Cardoso, município de Cananéia, litoral Sul de São Paulo, para a realocação da comunidade em face de um processo erosivo natural, que foi acelerado por um incidente com uma embarcação. Nesse processo, as mulheres acabaram por assumir um protagonismo, que, em certa medida, foi resultado de movimentos anteriores de empoderamento dessas mulheres por meio de sua inserção em atividades de economia solidária. Na perspectiva teórica, os autores acionam a categoria resistência como central, porém dialogando com o pensamento decolonial por meio das noções de r-existência, que se anuncia para além do resistir, mas na reafirmação da diversidade de identidades, racionalidades, 
territorialidades e modos de vida. Esses processos de r-existência se estabelecem na perspectiva da pluriversalidade.

Já Mafra (2019) apresenta um relato da importância assumida por uma liderança feminina na luta pelo território no município de Pontal do Paraná (PR). Em seu artigo "Desterritorialização e resistência em uma comunidade de pescadores no litoral do Paraná: a presença de uma liderança mulher na luta pelo território pesqueiro", o autor narra os repetidos processos de desalojamento e desterritorialização de uma comunidade de pescadores artesanais, empreendido pelo Estado, em face da presença desses em áreas da União. Nesse contexto que ganha destaque uma liderança feminina, que passa a protagonizar a resistência pelo território, fato potencializado pela posterior inserção da pescadora em movimentos sociais da pesca e que redundam na conquista da parte terrestre do território pesqueiro.

\section{População negra e quilombola e o lugar da educação}

Complementando as reflexões trazidas pelo conjunto dos textos desse dossiê temos os textos de Oliveira e Oliveira (2019), “À margem da história e da sociedade: a construção da cidadania e situação social dos afrodescendentes após a abolição da escravidão no Brasil” e de Moreira e Rosa (2019) "Colégio Estadual Quilombola Diogo Ramos: olhares sobre educação na Comunidade de João Surá". Estas contribuições trazem uma pertinente convergência - o papel da educação para a população negra no Brasil sob diferentes perspectivas. Enquanto Oliveira e Oliveira (2019) abordam a questão em uma perspectiva histórica, observando o acesso à educação como um elemento central na construção da cidadania para a população negra após a abolição da escravatura no início do século XX, Moreira e Rosa (2019) nos narram os caminhos para uma educação emancipadora em uma comunidade quilombola no Brasil contemporâneo.

Oliveira e Oliveira (2019) apontam para a ausência de acesso da população negra à direitos básicos como emprego, moradia e educação escolar nas quatro primeiras décadas após a abolição. Como explicitam no texto a partir de dados censitários, menos de 3\% da população negra sabia ler e escrever no ano de 1940, contra cerca de $30 \%$ da população branca. Destaca ainda como, após a abolição e o início do período republicano, o governo brasileiro estimula um processo imigratório de europeus para ocupar postos na agricultura - também com vistas ao branqueamento da população, ficando a população negra então "liberta" sem qualquer tipo de amparo ou compensação. As mudanças com novas políticas urbanas levam a novos processos de exclusão da população negra, que 
acaba por ter como espaço de moradia áreas periféricas e morros. A herança escravocrata se perpetua, assim, no sistema educacional do país, não garantindo o acesso universal da população.

Já Moreira e Rosa nos trazem um relato reflexivo de sua participação em um projeto na Comunidade Quilombola João Surá, no município de Adrianópolis, no estado do Paraná. As autoras participaram de atividades do Curso de Formação Pré-Acadêmica para ingresso à pós-graduação proposta pelo Núcleo de Estudos Afro-Brasileiros da Universidade Federal do Paraná (NEAB/UFPR), numa iniciativa de políticas de ações afirmativas para aumentar ingresso de alunos negros, pobres, indígenas, quilombolas e trans na Pós-graduação. Esse curso que estava acontecendo em Curitiba ganhou uma turma na comunidade, sendo o primeiro curso do gênero a ser realizado em um quilombo, que tinha como objetivo auxiliar uma turma de alunos quilombolas a ocuparem o espaço universitário. Por meio do grupo de Pesquisa Joana de Andrade, que há quatro anos desenvolve pesquisas sobre quilombo, educação e território em João Surá, ofereceram projetos de intervenção com os estudantes da educação infantil, ensino fundamental e médio durante a execução do curso, de tal forma que seria possível observar e participar com maior envolvimento, desde o fazer pedagógico até de que maneira a comunidade desenvolve e abraça a escola.

Como lições que trazem da educação quilombola na Comunidade João Surá, pode-se destacar a importância da ancestralidade e do aprender com os mais velhos, das práticas materiais e simbólicas, como a confecção de cestos e outros conhecimentos da própria comunidade, em diálogo com o saber escolar formal. É a perspectiva da pedagogia decolonial, como anuncia Walsh (2013), em que a memória coletiva se apresenta como um espaço onde se entretece a prática do pedagógico e do decolonial.

\section{À guisa de conclusão}

Neste número, trazemos contribuições que refletem sobre distintos temas interconexos pelas dimensões do gênero, do território e da decolonialidade. Os autores nos apresentam reflexões que convidam a pensar não apenas as formas de dominação e exploração instituídas pela ordem moderno/colonial, com suas formas de hierarquização racial, de gênero e de classe. Oferecem-nos também possibilidades de pensar formas de resistir e r-existir diante do sistema mundo capitalista, valorizando seus conhecimentos, saberes, práticas e racionalidades outras à pretensa razão universal eurocentrada. Seja nos campos, nas águas, no quilombo, os territórios e as mulheres anunciam outras 
formas possíveis de existir. Que possamos ampliar e repercutir essas experiências e perspectivas em nossas práticas políticas e acadêmicas. Boa Leitura!

\section{Referências}

ACSELRAD, H. Desigualdade ambiental, economia e política. Astrolábio, Cordoba, n.11, 2013.

BALLESTRIN, L. América Latina e o giro decolonial. Revista Brasileira de Ciência Política, Brasília, n. 11, p. 89-117, Ago 2013.

BELAUSTEGUIGOITIA RIUS, M. Indigenous Women and the Land: Shifting language, action and culture. Development, vol.54, no.4, 2011.

BORSANI, M.A; QUINTERO. P. Introducción. Los desafíos decoloniales de nuestros días: pensar en colectivo. In: BORSANI, M.A; QUINTERO, P. Los desafíos decoloniales de nuestros días: pensar en colectivo. Neuquén: EDUCO - Universidad Nacional del Comahue, 2014.

CABNAL, L. Acercamiento a la construcción de la propuesta de pensamiento epistémico de las mujeres indígenas feministas comunitarias de Abya Yala. Feminismos diversos: el feminismo comunitário, Madrid, Acsur Las Segovias, 2010, pp. 11-25.

CARNEIRO, F.F.; GIRALDO, L.; RIGOTTO, R.M.; FRIEDRICH, K.; BÚRIGO, A. (orgs). Dossiê ABRASCO: um alerta sobre os impactos dos agrotóxicos na saúde. Rio de Janeiro: EPSJV; São Paulo: Expressão Popular, 2015.

CRUZ HERNÁNDEZ, D.T. Una mirada muy otra a los territorios-cuerpos femininos. Solar, vol. 12, n.1, 2016.

DELGADO, G. Do capital financeiro na agricultura à economia do agronegócio: mudanças cíclicas em meio século (1965-2012). Porto Alegre: Editora da UFRGS, 2012.

ESCOBAR, A. Mas allá del desarrollo: postdesarrollo y transciones hacia el pluriverso. Revista de Antropología Social, Madrid, vol.21, 2012.

FAUSTINO, C.; PACHECO, T. A iniludível e desumana prevalência do racismo ambiental nos conflitos do mapa. IN: PORTO, M.F.; PACHO, T.; LEROY, J.P.. Injustiça e saúde no Brasil: o mapa de conflitos. Rio de Janeiro: Editora Fiocruz, 2013.

GROSFOGUEL, R. Para descolonizar os estudos de economia política e os estudos pós-coloniais: transmodernidade, pensamento de fronteira e colonialidade global. Revista Crítica de Ciências Sociais, n. 80, 2008, p. 115-147.

HARVEY, D. O novo imperialismo. 8a ed. São Paulo: Edições Loyola, 2014.

MACHADO ARAÓZ, H. El auge de la Minería transnacional en América Latina. De la ecología política del neoliberalismo a la anatomía política del colonialismo. In: ALIMONDA, H. La 
naturaleza colonizada: ecología política y minería en América Latina. Buenos Aires: Clacso, 2011.

MANRIQUE, L.H.R. (Neo)extrativismo e despojo no Sul Global: conflitos e resistências nos territórios. introdução. Revista Nera, Presidente Prudente, ano 18, nº. 28, 2015.

MCMICHAEL, P. Regimes alimentares e questões agrárias. São Paulo; Porto Alegre: Editora Unesp; Editora da UFRGS, 2016.

MERCHAND ROJAS, M.A. Neoextractivismo y conflictos ambientales en América Latina. Espiral, Guadalajara, v. 23, n. 66, p. 155-192, agosto 2016. Disponible en <http://www.scielo.org.mx/scielo.php?script=sci_arttext\&pid=S1665-

05652016000200155\&lng=es\&nrm=iso>.

MESZAROS, I. A crise estrutural do capital. São Paulo: Boitempo, 2009.

MIGNOLO, W. Retos decoloniales, hoy. IN: BORSANI, M.A; QUINTERO, P. Los desafíos decoloniales de nuestros días: pensar en colectivo. Neuquén: EDUCO - Universidad Nacional del Comahue, 2014.

PAREDES, J. Hilando Fino, desde el feminismo comunitario. Bolivia, La Paz: Comunidad Mujeres Creando Comunidad, 2011.

PAULILO, M. I. S. Movimento das mulheres agricultoras e os muitos sentidos da "igualdade de gênero". In: Bernardo Mançano Fernandes, Leonilde Servolo de Medeiros, Maria Ignez Paulilo (orgs.). Lutas camponesas contemporâneas: condições, dilemas e conquistas, v.2: a diversidade das formas das lutas no campo. São Paulo: Editora UNESP; Brasília, DF: Núcleo de Estudos Agrários e Desenvolvimento Rural, 2009. p. 179-201.

PLOEG, J.D.V. Sete teses sobre a agricultura camponesa. Dados e textos sobre a Luta pela Terra e a Reforma Agrária. 2008. Disponível em: http://www.reformaagrariaemdados.org.br/biblioteca/artigo-e-ensaio/sete-teses-sobre-agriculturacamponesa

PORTO-GONÇALVES, C.W; QUENTAL, P.A Colonialidade do poder e os desafios da integração regional na América Latina. Polis - Revista Latinoamericana, Santiago, no. 31, 2012.

QUIJANO, A. Colonialidade do poder, eurocentrismo e América Latina. In: LANDER, E. A colonialidade do saber, eurocentrismo e ciências sociais. Perspectivas latinoamericanas. Buenos Aires: CLACSO, 2005.

QUIJANO, A. "Bien vivir": entre el "desarrollo" y la des/colonialidad del poder. Horizontes sociologicos, Buenos Aires, no.1, 2015.

SANTOS, B.S. A crítica da razão indolente: contra o desperdício da experiência. $6^{a}$. ed. São Paulo: Editora Cortez, 2007.

SEGATO, R.L. Gênero e colonialidade: em busca de chaves de leitura e de um vocabulário estratégico descolonial. E-cadernos CES, Coimbra, no.18, 2012. 
SILIPRANDI, E. Mulheres e Agroecologia - Transformando o Campo, as Florestas e as Pessoas. Rio de Janeiro: Editora UFRJ, 2015.

WALSH, C. Lo pedagogico y lo decolonial: entretejiendo caminos. IN: WALSH, C. (org.). Pedagogías decoloniales: prácticas insurgentes de resistir, (re)existir y (re)vivir. Tomo I. Quito, Ecuador: Ediciones Abya-Yala, 2013. 